\title{
Is more frequent physical therapy associated with increased gross motor improvement in children with cerebral palsy? A national prospective cohort study.
}

Gunfrid V. Størvold ${ }^{\text {ae }}$, Reidun B. Jahnsen ${ }^{\text {bc }}$, Kari Anne I. Evensen ${ }^{\text {def }}$, Grete H. Bratberg ${ }^{\mathrm{eg}}$.

${ }^{a}$ Habilitation Centre, Nord-Trøndelag Hospital Trust, Levanger, Norway.

${ }^{b} \mathrm{CPOP}$, Department of Clinical Neuroscience for Children, Oslo University Hospital, Oslo, Norway.

${ }^{c}$ CHARM, Institute of Health and Society, University of Oslo, Oslo, Norway.

${ }^{d}$ Department of Clinical and Molecular Medicine, Norwegian University of Science and Technology (NTNU), Trondheim, Norway

${ }^{e}$ Department of Public Health and Nursing, Norwegian University of Science and Technology (NTNU), Trondheim, Norway

${ }^{f}$ Department of Physiotherapy, Trondheim Municipality, Trondheim, Norway

${ }^{g}$ Faculty of Nursing and Health Science, Nord University, Levanger, Norway.

Corresponding author: Gunfrid V. Størvold, HABU Nord-Trøndelag, Helse NordTrøndelag HF, Postboks 333, 7601 LEVANGER, Norway. Gunfrid.Storvold@hnt.no

Running head: Gross motor improvement in children with cerebral palsy. 


\section{Is more frequent physical therapy associated with increased gross motor improvement in children with cerebral palsy? A national prospective cohort study.}

Purpose: To investigate the association between physical therapy frequency and gross motor improvement in children with cerebral palsy.

Materials and methods: Prospective cohort study of 442 children aged 2-12 years, Gross Motor Function Classification System levels I-V, from the Cerebral Palsy Follow-up Program and the Cerebral Palsy Register of Norway. Outcome was change in Reference percentiles for the Gross Motor Function Measure (GMFM-66) between two subsequent assessments $(\mathrm{N}=1056)$ analyzed in a Linear Mixed Model.

Results: It was a dose response association between physical therapy frequency and gross motor improvement. Mean change was 4.2 (95\% CI: 1.4-7.1) percentiles larger for physical therapy 1-2 times per week and 7.1 (95\% CI: 2.611.6) percentiles larger for physical therapy $>2$ times per week, compared to less frequent physical therapy when analyzed in a multivariable model including multiple child and intervention factors. The only statistically significant confounder was number of contractures which was negatively associated with gross motor improvement.

Conclusion: When gross motor improvement is a goal for children with cerebral palsy, more frequent physical therapy should be considered.

Keywords: Cerebral palsy; physical therapy frequency; gross motor improvement; cohort; GMFM-66 reference percentiles; CPRN/CPOP 


\section{Is more frequent physical therapy associated with increased gross motor improvement in children with cerebral palsy? A national prospective cohort study.}

\section{Introduction}

Motor problems are the core symptom of cerebral palsy (CP) [1] and more than $90 \%$ of children with CP receive physical therapy; often directed at gross motor functions $[2,3]$. Many children with $\mathrm{CP}$ receive physical therapy 1-2 times per week [2, 3], but there are large variations ranging from less than twice per month to more than three times per week [3]. Considering the time and effort that children and their families invest in gross motor skills practice and prevention strategies of secondary impairments, it is important to know whether more frequent physical therapy really constitutes a success factor for increased gross motor improvement [4].

According to current recommendations, therapy should be based on motor learning principles, including goal-directed, task-specific practice with frequent repetitions $[4,5,6,7]$, which have shown to enhance gross motor improvement $[6,8,9$, 10]. Which role the physical therapy frequency in itself may play for gross motor improvement however, is still largely unclear $[4,11,12,13,14]$, although some recent studies have suggested that therapies of higher frequencies are more effective than others $[15,16]$. Since the frequency add to the total dose of physical therapy [17], one should expect increased frequency to enhance gross motor improvement. However, according to a recent systematic review, there is "insufficient evidence to support implementing high-dose therapy" [11]. On the other hand, this knowledge is based on relatively few randomized controlled trials (RCTs) including small and selected samples. Studies based on larger cohorts of children have been sparse. However, in a recently published study from our research group, based on the same study cohort as in 
the present study, results suggested a more positive long-term gross motor developmental trajectory for children receiving intensive training compared to counterparts [18].

According to systems theory of motor control [5] and the International Classification of Functioning, Disability and Health (ICF) [19] gross motor improvement is considered the net result of the interactions between several factors including, but not limited to, Gross Motor Function Classification System (GMFCS) level [20], age, physical therapy frequency, contractures, associated problems, comorbidities and other types of interventions. Therefore, in order to study the role of physical therapy frequency on gross motor improvement, other factors should be considered as possible confounders. Of special interest is contractures which can contribute to the deterioration of functional skills [21] and thus be negatively associated with gross motor improvement $[14,22]$. Contractures are therefore commonly addressed in therapy in order to lessen the negative effect on gross motor outcome [23, 24].

Associated problems such as intellectual disability, speech problems, eating problems, severe visual and hearing problems, and pain; epilepsy and additional diagnoses $[14,22,25]$ generally add to the total health and functional burden of the child, and may not only be negatively associated with gross motor improvement, but may also limit the child's availability for physical therapy.

Furthermore, interventions other than physical therapy may contribute to gross motor improvement. Botulinum toxin A (BoNT-A) injections, intrathecal baclofen (ITB), surgery, and use of orthoses have shown to affect body function and structures, but there is not convincing evidence of a direct influence on gross motor function and progress [6]. Some children may also participate in an intensive program of shorter 
duration in addition to the regular physical therapy, which may increase the total dose of physical therapy.

There has been a call for research using large data sets to provide information about how prognostic factors influence the outcomes of persons with $\mathrm{CP}[5,26]$. By using data from the Cerebral Palsy Follow-up Program (CPOP) and the Cerebral Palsy Register of Norway (CPRN), we are now able to investigate the role physical therapy frequency may play for gross motor improvement in a large cohort of children during childhood (2-12 years). The longitudinal design with multiple assessments per child and the use of the Reference percentiles for the Gross Motor Function Measure (GMFM-66 percentiles) [27] as outcome, make it possible to estimate change between two subsequent assessments and directly compare gross motor improvement across ages and GMFCS levels.

\author{
Aim \\ The aim of this study was to investigate the association between physical therapy \\ frequency and gross motor improvement in a large cohort of children with $\mathrm{CP}$, taking \\ contractures and other available potential confounders into account. We hypothesize \\ that there is a positive association between more frequent physical therapy and \\ increased gross motor improvement, and that number of contractures and possibly some \\ of the other factors will affect this association.
}

\title{
Materials and methods
}

\section{Design and participants}

This prospective cohort study is based on repeated (time-dependent) data from CPOP and time-independent data from CPRN. Health professionals working at the 21 
habilitation centers, serving all children diagnosed with $\mathrm{CP}$ in Norway, are submitting clinically obtained data to these consent-based registers [28].

CPRN is a national medical quality register including children born in 1996 or later [28]. Data are recorded at three ages (time of diagnoses, 5 years and 15 years) [28]. CPOP includes children born in 2002 or later. Data are recorded once or twice per year until 6 years of age, thereafter yearly or every second year, depending on the child's GMFCS level.

Approximately $90 \%$ of children with CP born after 2002 in Norway are included in CPRN/CPOP [28].

\section{Inclusion and exclusion}

In order to investigate change in gross motor function, children registered in both CPOP and CPRN with two or more assessments of Gross Motor Function Measure (GMFM66) [29] between the ages of 2 and 12 years (the age span for GMFM-66 percentiles) were eligible to participate. Of the 1088 children included in CPOP born between 2002 and 2013, 442 children aged 2 to 12 years ( 256 boys, 186 girls) fulfilled the inclusion criteria. The excluded children were either too young to have completed two assessments, or GMFM-66 assessments were missing due to work overload of assessors. In total, there were 1498 GMFM-66 assessments (2-9 per child), and thus 1056 measures of change in GMFM-66 percentiles (1-8 measures of change per child, mean: 2.4 SD: 1.6). Time between two subsequent GMFM-66 assessments was median 1 year (interquartile range: 0.73 to 1.42 years) and mean 1.23 years (SD: 0.81 ).

The characteristics of the children in the study cohort (Table 1) were comparable with the source population of Norwegian children with $\mathrm{CP}$ registered in CPOP/CPRN (Annual reports of CPOP and CPRN 2014) [30] with no statistically significant differences. 
Table 1

\section{Measures}

Data from CPOP are linked to CPRN once per year giving a hierarchical file with timeindependent characteristics of each child on one level and repeated (time-dependent) measures of each child on a second level. For our study, we included repeated measures of GMFM-66 percentiles, physical therapy frequency, contractures, pain, treatmentrelated variables and age (Figure 1). We included time-independent measures of CP subtype, GMFCS level, associated problems, and comorbidities based on the 5 year assessment in CPRN when subdiagnosis is confirmed (Figure 1). Time-independent variables (child characteristics not considered to vary from time to time) were considered valid for all assessments for that particular child. Each assessment for a child therefore included data on both the time-independent variables and the time-dependent variables.

Figure 1

\section{Dependent variable}

Gross motor change was defined as the mean change in GMFM-66 percentiles [27] from one assessment to the next ( $\Delta$ percentiles), and gross motor improvement as a positive change in GMFM-66 percentiles from one assessment to the next.

Gross motor function was repeatedly measured with GMFM-66 [29] and the total scores were converted to GMFM-66 percentiles using tabulated reference percentiles [31] according to age and GMFCS level [20]. Both GMFCS and GMFM-66 have been found valid and reliable [20, 29].

Based on the Motor development curves [32] that have been validated in Norway [33], the GMFM-66 percentiles show the expected patterns of change in 
GMFM-66 total scores by age within each GMFCS level [27]. GMFM-66 percentiles provide a standardized measure of change across ages and GMFCS levels accounting for the fact that a change in GMFM-66 total scores does not correspond to the same change in GMFM-66 percentile for different ages and GMFCS levels [31].

Despite large variation [27], children are in general expected to follow their percentile. Hence, a positive change in GMFM-66 percentile imply a gross motor development better than expected; that is, a better relative standing compared to other children at same age and GMFCS level [27], which has the same interpretation for all children with CP. For most children a positive change in GMFM-66 percentiles indicates a larger increase in GMFM-66 total scores than expected. However, since the shapes of GMFM-66 reference percentile curves differ, [31] an increase in percentile for older children functioning on the lower percentiles may imply that the expected decrease in GMFM-66 total scores has been smaller than expected.

GMFM-66 percentiles have been used as outcome measure both in intervention studies $[8,34]$ and in a prospective cohort study [18].

\section{Independent variables}

Physical therapy frequency was recorded at each assessment by answering how often the child had had physical therapy (direct contact with the physical therapist) since last assessment on a five-point ordinal scale: less than 1 time per month, 1-3 times per month, 1-2 times per week, 3-5 times per week and more than 5 times per week [30]. In order to extract as much information as possible, the original scale was used in the exploration of data and in descriptive analyses. Due to the restricted numbers of recordings in the upper end of the scale however, frequency was collapsed into a threepoint scale for further analyses: $<1$ time per week, $1-2$ times per week and $>2$ times per week. Registry data does not provide information about type of physical therapy. We 
therefore had to characterize it as conventional therapy, although we acknowledge that therapy often is highly goal-directed and functional [35].

Contractures in lower limbs. Passive range of motion (ROM) was measured repeatedly with a goniometer in a standardized way according to CPOP guidelines [30], in hips (extension, inward rotation, outward rotation, and abduction), knees (extension, unilateral popliteal angle) and ankles (dorsiflexion with extended knee). Then CPOP guidelines [30] for defining contractures were applied. Thereafter number of contractures in the most affected leg were trichotomized into no contractures, 1-2 contractures, or $>2$ contractures.

Other independent variables. Pain was classified as "present" or "not present" at each assessment. All interventions targeting impairments (BoNT-A, ITB, surgery in lower limbs or use of orthoses) were dichotomized as "having received the intervention" or "not received the intervention" since the last assessment. Participation in an intensive program since the last assessment was classified as "yes" or "no". There was no further information about intensive program except from involving some form of intensive gross motor training (e.g. local, regional or national functional programs, and a few conceptual programs; often with daily training over 3-6 weeks) in addition to the regular physical therapy.

CP subtype was classified according to The Surveillance of Cerebral Palsy in Europe (SCPE) [36]. Intellectual ability is recorded by a range of standardized instruments or by clinical judgements. This information was combined and dichotomized into "intellectual disability" (including moderate to severe intellectual disability) or "not intellectual disability" (no or minor intellectual disability). Speech was recorded on an ordinal 5-point scale and dichotomized into "understandable speech" or "not understandable speech". Eating problems were dichotomized as 
"present" or "not present". Severe visual and severe hearing problems were recorded dichotomously, combined, and recoded as "severe visual and/or severe hearing problem" or "not severe visual and/or severe hearing problem". Associated health conditions were dichotomized and classified as "present" or "not present" for epilepsy and additional diagnoses (mostly syndromes including Trisomi 21 and De George syndrome).

An overview of the independent variables, the coding/recoding and the studyspecific classifications are provided in Table 2. Age and GMFCS level are accounted for in the GMFM-66 percentiles and therefore not listed as independent variables.

Table 2

\section{Statistics}

The statistical analyses were performed using SPSS, version 24. The significance level was set at 0.05 . Descriptive statistics was used to generate frequencies and central tendencies. Possible differences in characteristics between the study cohort and the source population were tested by the use of Chi-square and Fisher exact tests (missing categories not included).

In order to avoid collinearity between independent variables, we conducted correlation analyses. "Speech problems" was excluded due to the high correlation with "intellectual disability" ( $\mathrm{r}=0.88$; cut-off 0.7$)$.

The association between physical therapy frequency and gross motor improvement was analyzed using Linear Mixed Model (LMM) with change in GMFM66 percentiles between two subsequent assessments ( $\Delta$ percentiles) as dependent variable. The possibility of within-subject correlation in the dependent variable was accounted for by including a random intercept for child. 
We first investigated the role of physical therapy frequency (three-point scale) on gross motor improvement with number of contractures as confounder based on complete cases (assessments with no missing data in any of the included variables, $\mathrm{n}=814$ ). Physical therapy frequency and number of contractures were included as fixed effects in the model. A possible interaction between physical therapy frequency and number of contractures was explored, but not found. No random effects were found. Also, unadjusted results based on the same data set were calculated and model fit explored using -2 Restricted Log Likelihood (the less the better) confirming that the model including number of contractures had better model fit (6904.971 vs 6920.350).

Due to the cumulative effect of missing values in multiple variables, multiple imputations were performed in order to keep the data set large enough to include all possible confounders in the model. Missing data were assumed to be missing at random as missing data mainly were due to factors related to assessors (work overload) and not to factors related to the children. Both the dependent and independent variables were included in the imputation model to predict the missing values. In order to ensure that all LMM analyzes were performed on the same data set, the dependent variable, physical therapy frequency and number of contractures were not imputed. Automatic procedures that allow imputation method to be chosen based on scanning of data were applied, leading to the use of the "Fully Conditional Specification Method." Categorical variables were modeled with a logistic regression model. Each model used all variables as main effect and no interaction effects were included.

The role of physical therapy frequency on gross motor improvement was then investigated in a multivariable model based on the imputed data set (pooled imputations from 20 imputations, $n=814$ ) including both number of contractures and all of the other independent variables that possibly could influence the research question as fixed 
effects. No random effect or interactions were found. Both the unadjusted, the adjusted, and the multivariable adjusted model are presented.

The estimated marginal means based on the multivariable model were used to create Figure 2.

\section{Ethics}

Ethical approval was given by the Regional Committee for Medical and Health Research Ethics in central Norway (2014/1484/REK midt) and the institutional board of Nord Trøndelag Hospital Trust. The registers providing data for this study are based on informed consent from parents.

\section{Results}

\section{Physical therapy frequency}

A total of 431 of the 442 children had one or more assessments of physical therapy frequency (total 987 assessments). In $61 \%$ of the cases, children received physical therapy 1-2 times per week, $11 \%$ more often and $28 \%$ less often (Table 3). Higher frequencies of physical therapy were more common among children on GMFCS levels III and V (Table 3).

\section{Table 3}

\section{Gross motor improvement in general}

Results based on 1056 assessments of change showed that the 442 children largely followed their percentiles as the median change in GMFM-66 percentiles between two subsequent assessments (median 1 year) was 0 percentiles (interquartile range: -5 to 10 , mode: 0$)$. The mean change was 2.51 percentiles (SD: 17.45$)$. 


\section{Association between physical therapy frequency and gross motor improvement}

Results based on complete cases $(n=814)$ showed a positive association between more frequent physical therapy and increased gross motor improvement $(\mathrm{p}=0.003)$ when adjusted for number of contractures, which was negatively associated with gross motor improvement $(\mathrm{p}=0.008)$ (Table 4).

Table 4

Multivariable adjusted results (number of contractures, epilepsy, intellectual disability, pain, eating problems, visual and/or hearing problems, type of CP, participating in an intensive program, BoNT-A, ITB, surgery, using orthoses and additional diagnoses) based on imputed data $(\mathrm{n}=814)$ showed similar results as the model adjusted for number of contractures (Table 4). Compared to the references (physical therapy < once per week), gross motor improvement was on average 4.2 (95\% CI: 1.4 to 7.1$)$ percentiles larger for children receiving physical therapy 1-2 times per week and 7.1 (95\% CI: 2.6 to 11.6) percentiles larger for children receiving physical therapy more than 2 times per week. Of possible confounding factors included in final model only number of contractures remained statistically significant, whereas epilepsy had a p-value of 0.052. Both number of contractures and epilepsy were negatively associated with gross motor improvement. The multivariable adjusted estimated marginal means for change in GMFM-66 percentile were -3.4 (95\% CI: -9.6 to 2.8) percentiles for physical therapy <once per week, 0.8 (95\% CI: -4.9 to 6.5) percentiles for physical therapy 1-2 times per week and 3.7 (95\% CI: -2.7 to 10.1) percentiles for physical therapy $>2$ times per week.

Figure 2 shows the multivariable adjusted estimated mean changes in GMFM-66 percentiles related to physical therapy frequency and number of contractures, showing a 
more fortunate change for children having more frequent physical therapy not having contractures.

Figure 2

\section{Discussion}

In this large cohort study based on the high-coverage CPOP and CPRN registers we found that more frequent physical therapy was associated with increased gross motor improvement. Contractures represented an obstacle to gross motor improvement.

Our results suggest that in order to improve gross motor function, the actual physical therapy frequency matters. These results are in accordance with motor learning theories highlighting the need for high-frequent repetitions for motor learning to occur $[4,5,6,7]$, and are also in line with findings in intervention studies based on such theories $[6,8,9,10]$ and with a recent long-term cohort study [18].

The most recent systematic review of the effect of physical therapy frequency on motor outcomes in children with $\mathrm{CP}$, however, concluded that there was not enough evidence to determine whether therapies with higher frequencies were more effective than low frequent therapies [11]. On the other hand, this conclusion is predominantly based on results from a few RCTs [11]. Although RCT studies generally are considered the best study design, there are several ethical reservations, especially in studies of children. Since not all children will be available for inclusion in experimental studies, it may be difficult to generalize the results. In contrast, the inclusion of all children in the present study is suggested to give a reliable real-life picture of the relationship between physical therapy frequency and gross motor improvement. Although the association cannot be deemed causal, our findings suggest a dose response association between physical therapy frequency and gross motor improvement. In fact, if gross motor improvement is the goal, frequencies above 2 times per week should be provided. Low- 
frequency physical therapy ( $<1$ time per week) may not be recommended according to this study.

The gross motor improvements associated with the increases in percentiles found in this study (Figure 2) have different clinical interpretation for different GMFCS levels and ages. For example, a change from the $45^{\text {th }}$ to the $50^{\text {th }}$ percentile over a year for a 5 year old child at GMFCS level I, corresponds to an increase of 4,9 points in GMFM-66 total score, and thus a large meaningful clinically significant change [37] [38].

Our findings suggest that the impact of more frequent physical therapy may vary depending on number of contractures. This was not unexpected, given the results of earlier research, which indicate that the secondary impairment of contractures in lower limbs is negatively associated with gross motor function $[14,22]$. We hypothesize that this may be due to the fact that contractures complicate both the performing and the learning of gross motor skills, but may also be a result of that therapies to a greater extent are addressing the contractures with less focus on gross motor skills learning.

Although it is suggested that associated problems negatively influence gross motor function $[14,22,25]$, we found that may be except from epilepsy $(\mathrm{p}=0.052)$, no other associated problems included in analyzes were of relevance for the association between physical therapy frequency and gross motor improvement. This result indicates that most children, independent of the presence of associated problems, may benefit from higher frequencies of physical therapy. Having said that; this study does not investigate the complicated question of when to prioritize gross motor function in therapy. In our opinion this decision has to be taken in close collaboration with the child (age dependent) and parents. Also, one has to carefully consider when the child shows 
an attempt to master a new gross motor function, is in danger of losing functions or developing secondary impairments among other things.

The participation in a short-term intensive program in addition to the regular physical therapy was considered to increase the total dose of therapy, and a small nonsignificant positive association was found with gross motor improvement. However, the inclusion of this variable in the model did not affect the association between the frequency of regular physical therapy and gross motor improvement. Also, interventions that address impairments did not affect the association between physical therapy frequency and gross motor improvement. This finding is in accordance with previous research that have hypothesized that although these interventions may influence impairments, they may not directly improve gross motor function [6].

\section{Strengths and limitations}

The prospective study design, including a large national representative cohort of 442 children aged 2-12 years, is considered strength of this study. The use of repeated standardized measurements of gross motor function is suggested to increase the internal validity and the precision of estimates. The access to a range of other variables of relevance for the study question and the multivariable approach generate hypotheses about the role physical therapy frequency may play for gross motor improvement. The use of GMFM-66 percentiles in studies of gross motor change is also considered strength since percentiles can be interpreted equally across different GMFCS levels and ages.

Multiple environmental, parental and personal factors may affect gross motor progress [22] and the unavailability of data on such factors is considered a limitation as is the lack of data on type of physical therapy. Also, therapy as practice of everyday skills may be integrated into daily routines, thereby providing additional therapy that we 
were not able to take into account. Furthermore, session length and weeks of physical therapy per year may vary. However, most session lengths are found to be 30-60

minutes [3] and the duration of physical therapy in this study is not expected to systematically vary between frequencies. Nor did we expect large systematic variations in weeks of physical therapy per year as Norway have a public school and health care system.

\section{Conclusion}

Our results suggest that when gross motor improvement is prioritized, high-frequency physical therapy should be considered for children with CP.

Acknowledgements

We thank all the children and their families who participate in CPRN and CPOP and thus made our research possible. The main funding for the study was provided by the Sophie Minde Foundation. One of the authors (Dr Jahnsen) also received a minor contribution from the Norwegian Fund for Post-graduate Training in Physiotherapy.

Declaration of interest

The authors report no conflicts of interest.

Word count: 3808 


\section{References}

1. Rosenbaum P, Paneth N, Leviton A, et al. A report: the definition and classification of cerebral palsy April 2006. Dev Med Child Neurol Suppl. 2007 Feb;109:8-14. PubMed PMID: 17370477.

2. Myklebust G, Jahnsen R, Elkjaer S. Registration of interventions in children with cerebral palsy during three years-a populationbased study. [Scientific Poster Abstracts]. Developmental Medicine \& Child Neurology. 2009;51:65. doi: 10.1111/j.1469-8749.2009.03452_2.x.

3. Palisano R, Begnoche DM, Chiarello LA, et al. Amount and focus of physical therapy and occupational therapy for young children with cerebral palsy. Physical \& occupational therapy in pediatrics. 2012 Nov;32(4):368-82. doi: 10.3109/01942638.2012.715620. PubMed PMID: 22954372.

4. Novak I. Evidence to practice commentary: is more therapy better? Physical \& occupational therapy in pediatrics. 2012;32(4):383-387.

5. Law M, Darrah J. Emerging Therapy Approaches: An Emphasis on Function. Journal of child neurology. 2014 May 7. doi: 10.1177/0883073814533151. PubMed PMID: 24810086.

6. Novak I, McIntyre S, Morgan C, et al. State of the evidence: systematic review of interventions for children with cerebral palsy. Developmental medicine and child neurology. 2013;55. doi: 10.1111/dmcn.12246.

7. Novak I. Evidence-based diagnosis, health care, and rehabilitation for children with cerebral palsy. Journal of child neurology. 2014;29(8):1141-1156.

8. Lowing K, Bexelius A, Carlberg EB. Goal-directed functional therapy: a longitudinal study on gross motor function in children with cerebral palsy. Disability and rehabilitation. 2010;32(11):908-16. doi: 10.3109/09638280903353422. PubMed PMID: 19852713.

9. Bleyenheuft Y, Arnould C, Brandao MB, et al. Hand and Arm Bimanual Intensive Therapy Including Lower Extremity (HABIT-ILE) in Children With Unilateral Spastic Cerebral Palsy: A Randomized Trial. Neurorehabil Neural Repair. 2015;29(7):645-657. doi: 10.1177/1545968314562109.

10. Bleyenheuft Y, Ebner-Karestinos D, Surana B, et al. Intensive upper- and lowerextremity training for children with bilateral cerebral palsy: a quasi-randomized trial. Developmental medicine and child neurology. 2017 Jun;59(6):625-633. doi: 10.1111/dmcn.13379. PubMed PMID: 28133725; eng.

11. Cope S, Mohn-Johnsen S. The effects of dosage time and frequency on motor outcomes in children with cerebral palsy: A systematic review. Developmental neurorehabilitation. 2017:1-12.

12. Myrhaug HT, Østensjø S, Larun L, et al. Intensive training of motor function and functional skills among young children with cerebral palsy: a systematic review and meta-analysis. BMC pediatrics. 2014;14(1):292.

13. Arpino C, Vescio MF, De Luca A, et al. Efficacy of intensive versus nonintensive physiotherapy in children with cerebral palsy: a meta-analysis. Int J Rehabil Res. 2010 Jun;33(2):165-71. doi: 10.1097/MRR.0b013e328332f617. PubMed PMID: 19910797.

14. Chiarello LA, Palisano RJ, Bartlett DJ, et al. A multivariate model of determinants of change in gross-motor abilities and engagement in self-care and play of young children with cerebral palsy. Physical \& occupational therapy in 
pediatrics. 2011 May;31(2):150-68. doi: 10.3109/01942638.2010.525601. PubMed PMID: 20964514.

15. Park EY. Effect of physical therapy frequency on gross motor function in children with cerebral palsy. Journal of physical therapy science. 2016 Jun;28(6):1888-91. doi: 10.1589/jpts.28.1888. PubMed PMID: 27390440; PubMed Central PMCID: PMCPMC4932081. eng.

16. Lee SH, Shim JS, Kim K, et al. Gross Motor Function Outcome After Intensive Rehabilitation in Children With Bilateral Spastic Cerebral Palsy. Annals of rehabilitation medicine. 2015 Aug;39(4):624-9. doi: 10.5535/arm.2015.39.4.624. PubMed PMID: 26361600; PubMed Central PMCID: PMCPMC4564711. eng.

17. Palisano RJ, Murr S. Intensity of therapy services: what are the considerations? Physical \& occupational therapy in pediatrics. 2009;29(2):107-12. doi: 10.1080/01942630902805186. PubMed PMID: 19401925.

18. Størvold GV, Jahnsen RB, Evensen KAI, et al. Factors Associated with Enhanced Gross Motor Progress in Children with Cerebral Palsy: A RegisterBased Study. Physical \& occupational therapy in pediatrics. 2018:1-14. doi: 10.1080/01942638.2018.1462288.

19. WHO. International classification of functioning, disability and health: ICF. Organization WH, editor.: World Health Organization; 2001.

20. Palisano R, Rosenbaum P, Walter S, et al. Development and reliability of a system to classify gross motor function in children with cerebral palsy. Developmental medicine and child neurology. 1997 Apr;39(4):214-23. PubMed PMID: 9183258; eng.

21. Nordmark E, Hagglund G, Lauge-Pedersen H, et al. Development of lower limb range of motion from early childhood to adolescence in cerebral palsy: a population-based study. BMC Med. 2009 Oct 28;7:65. doi: 10.1186/1741-70157-65. PubMed PMID: 19863779; PubMed Central PMCID: PMCPMC2774339.

22. Bartlett DJ, Chiarello LA, McCoy SW, et al. Determinants of gross motor function of young children with cerebral palsy: a prospective cohort study. Developmental medicine and child neurology. 2014 Mar;56(3):275-82. doi: 10.1111/dmcn.12317. PubMed PMID: 24127787.

23. Jeffries L, Fiss A, McCoy SW, et al. Description of Primary and Secondary Impairments in Young Children With Cerebral Palsy. Pediatric physical therapy : the official publication of the Section on Pediatrics of the American Physical Therapy Association. 2016 Spring;28(1):7-14. doi: 10.1097/PEP.0000000000000221. PubMed PMID: 27088676.

24. Anaby D, Korner-Bitensky N, Steven E, et al. Current Rehabilitation Practices for Children with Cerebral Palsy: Focus and Gaps. Physical \& occupational therapy in pediatrics. 2016:1-15.

25. Beckung E, Hagberg G, Uldall P, et al. Probability of walking in children with cerebral palsy in Europe. Pediatrics. 2008 Jan;121(1):e187-92. doi: 10.1542/peds.2007-0068. PubMed PMID: 18070932.

26. Kruijsen-Terpstra AJ, Ketelaar M, Verschuren O, et al. Determinants of developmental gain in daily activities in young children with cerebral palsy. Physical \& occupational therapy in pediatrics. 2015;35(3):265-279.

27. Hanna SE, Bartlett DJ, Rivard LM, et al. Reference curves for the Gross Motor Function Measure: percentiles for clinical description and tracking over time among children with cerebral palsy. Physical therapy. 2008 May;88(5):596-607. doi: 10.2522/ptj.20070314. PubMed PMID: 18339799; PubMed Central PMCID: PMC2390723. 
28. Hollung SJ, Vik T, Wiik R, et al. Completeness and correctness of cerebral palsy diagnoses in two health registers: implications for estimating prevalence.

Developmental Medicine \& Child Neurology. 2016:n/a-n/a. doi: 10.1111/dmcn.13341.

29. Russell DJ, Rosenbaum P, Wright M, et al. Gross motor function measure (gmfm-66 and gmfm-88): user's manual. London: Mac Keith Press; 2013.

30. CPOP. Cerebral Parese Oppfølgingsprogram Norway[cited 201723 05]. Available from: https://oslo-universitetssykehus.no/avdelinger/barne-ogungdomsklinikken/barneavdeling-for-nevrofag/cpop-cerebral-pareseoppfolgingsprogram

31. Hanna SE, Bartlett D, Rivard LM, et al. Tabultated reference percentiles for the 66-item Gross Motor Function Measure for use with children having cerebral palsy. www.canchild.ca2008 [cited 2016].

32. Rosenbaum P, Walter SD, Hanna SE, et al. Prognosis for gross motor function in cerebral palsy: creation of motor development curves. JAMA : the journal of the American Medical Association. 2002 Sep 18;288(11):1357-63. PubMed PMID: 12234229.

33. Myklebust G, Jahnsen R, Elkjaer S. Development of gross motor function in children with cerebral palsy: an investigation of 'motor growth curves'.

Developmental Medicine \& Child Neurology. 2014;56:39-112. doi: 10.1111/dmcn.12540.

34. Storvold GV, Jahnsen R. Intensive motor skills training program combining group and individual sessions for children with cerebral palsy. Pediatric physical therapy : the official publication of the Section on Pediatrics of the American Physical Therapy Association. 2010 Summer;22(2):150-9. doi: 10.1097/PEP.0b013e3181dbe379. PubMed PMID: 20473097.

35. Myrhaug HT, Ostensjo S. Motor Training and Physical Activity Among Preschoolers with Cerebral Palsy: A Survey of Parents' Experiences. Physical \& occupational therapy in pediatrics. 2013 Jul 10. doi: 10.3109/01942638.2013.810185. PubMed PMID: 23841711.

36. Cans C, Dolk H, Platt M, et al. Recommendations from the SCPE collaborative group for defining and classifying cerebral palsy. Developmental Medicine \& Child Neurology. 2007;49(s109):35-38.

37. Oeffinger D, Bagley A, Rogers S, et al. Outcome tools used for ambulatory children with cerebral palsy: responsiveness and minimum clinically important differences. Developmental medicine and child neurology. 2008 Dec;50(12):918-25. doi: 10.1111/j.1469-8749.2008.03150.x. PubMed PMID: 19046185; PubMed Central PMCID: PMCPMC2990955.

38. Wang H-Y, Yang YH. Evaluating the Responsiveness of 2 Versions of the Gross Motor Function Measure for Children With Cerebral Palsy. Archives of Physical Medicine and Rehabilitation. 2006;87(1):51-56. doi: 10.1016/j.apmr.2005.08.117. 
Figure captions:

Figure 1: Overview of time-independent and time-dependent variables and the hierarchical structure of the data file.

Figure 2: Multivariable* adjusted estimated mean changes in GMFM-66 percentiles according to physical therapy frequency and number of contractures for children with CP 2-12 years.

* Also adjusted for epilepsy, intellectual disability, pain, eating problems, visual and/or hearing problems, type of $\mathrm{CP}$, participating in an intensive program, BoNT-A, ITB, surgery, using orthoses and additional diagnoses $(n=814)$. 
Table 1. Characteristics of the study cohort and the source population CPOP / CPRN

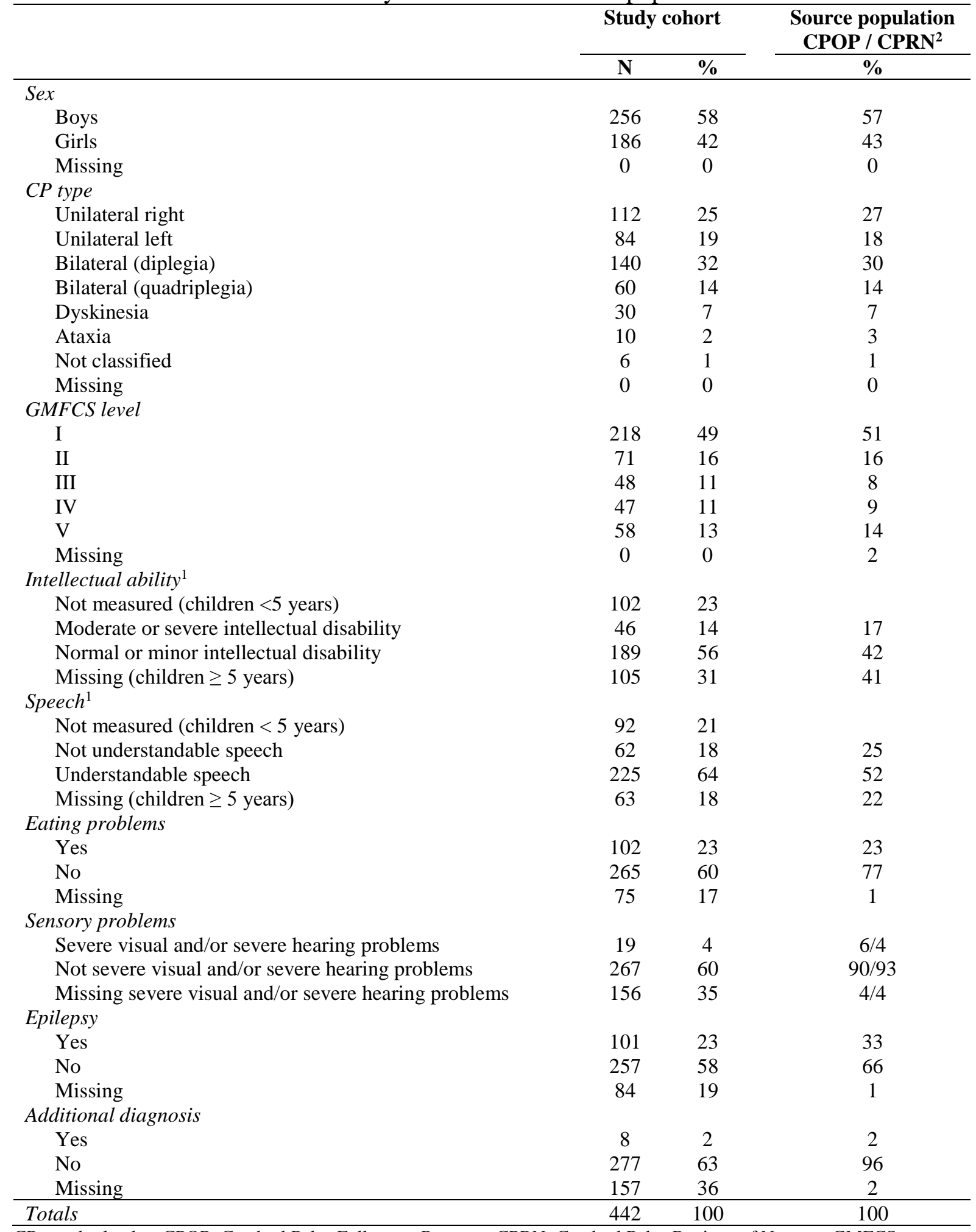

CP: cerebral palsy. CPOP: Cerebral Palsy Follow-up Program, CPRN: Cerebral Palsy Register of Norway, GMFCS:

Gross Motor Function Classification System.

${ }^{1}$ Intellectual ability and speech only assessed in children aged $\geq 5$ years

${ }^{2}$ Information from annual reports of CPOP and CPRN 2014.

Differences between study and source cohorts were calculated by the use of Chi Square and Fisher exact test. No characteristics differed statistically significantly between the study and the source cohort. 
Table 2. Description of independent variables

\section{Repeated (time-dependent) measures}

\begin{tabular}{|c|c|c|c|c|}
\hline Variables & Original variables & Classifications / recoding & & $\begin{array}{c}\text { Observations } \\
\text { n }\end{array}$ \\
\hline \multirow[t]{5}{*}{ Physical therapy frequency } & Ordinal: > 5 times per week & Recoded: & $>2$ times per week & 110 \\
\hline & 3-5 times per week & & 1-2 times per week & 601 \\
\hline & 1-2 times per week & & $<$ once per week & 276 \\
\hline & $1-3$ times per month & & Missing & 69 \\
\hline & $<$ once per month & & & \\
\hline \multirow[t]{6}{*}{ Contractures in lower limbs } & Range of motion (ROM) & \multirow{2}{*}{\multicolumn{2}{|c|}{$\begin{array}{l}\text { Classified into "Contracture or no contracture (normal } \\
\text { and to be followed according to CPOP manual)" for the } \\
7 \text { possibilities. }\end{array}$}} & \\
\hline & $\begin{array}{l}\text { Scale variable of degrees measured with goniometer at } \\
\text { hip, (abduction, extension, in/outward rotation), }\end{array}$ & & & \\
\hline & knee (extension, popliteal angle) and & \multirow[t]{4}{*}{ Recoded: } & $>2$ contractures & 75 \\
\hline & ankle (dorsiflexion with extended knee) in most affected & & 1-2 contractures & 352 \\
\hline & leg & & No contractures & 439 \\
\hline & & & Missing & 190 \\
\hline \multirow[t]{3}{*}{ Pain } & Dichotomous: Yes/No & \multirow{3}{*}{ Original variable and coding } & Yes & 297 \\
\hline & & & No & 722 \\
\hline & & & Missing & 37 \\
\hline \multirow{3}{*}{$\begin{array}{l}\text { Botulinum toxin (BoNT-A) in } \\
\text { lower limbs }\end{array}$} & \multirow[t]{3}{*}{ Dichotomous: Yes/No } & \multirow[t]{3}{*}{ Original variable and coding } & Yes & 297 \\
\hline & & & No & 714 \\
\hline & & & Missing & 45 \\
\hline \multirow[t]{3}{*}{ Intrathecal baclofen (ITB) } & \multirow[t]{3}{*}{ Dichotomous: Yes/No } & \multirow[t]{3}{*}{ Original variable and coding } & Yes & 21 \\
\hline & & & No & 961 \\
\hline & & & Missing & 74 \\
\hline \multirow[t]{3}{*}{ Surgery in lower limbs } & \multirow[t]{3}{*}{ Dichotomous: Yes/No } & \multirow[t]{3}{*}{ Original variable and coding } & Yes & 62 \\
\hline & & & No & 966 \\
\hline & & & Missing & 28 \\
\hline \multirow{3}{*}{$\begin{array}{l}\text { Use of orthoses in foot, ankle, } \\
\text { knee, or hip }\end{array}$} & \multirow[t]{3}{*}{ Dichotomous: Yes/No } & \multirow[t]{3}{*}{ Original variable and coding } & Yes & 785 \\
\hline & & & No & 231 \\
\hline & & & Missing & 40 \\
\hline \multirow[t]{3}{*}{ Intensive program } & \multirow{3}{*}{$\begin{array}{l}\text { Participation in an intensive program: Dichotomous: } \\
\text { Yes/no }\end{array}$} & \multirow[t]{3}{*}{ Original variable and coding } & Yes & 437 \\
\hline & & & No & 525 \\
\hline & & & Missing & 94 \\
\hline
\end{tabular}




\section{Time-independent variables (frequencies in Table 1)}

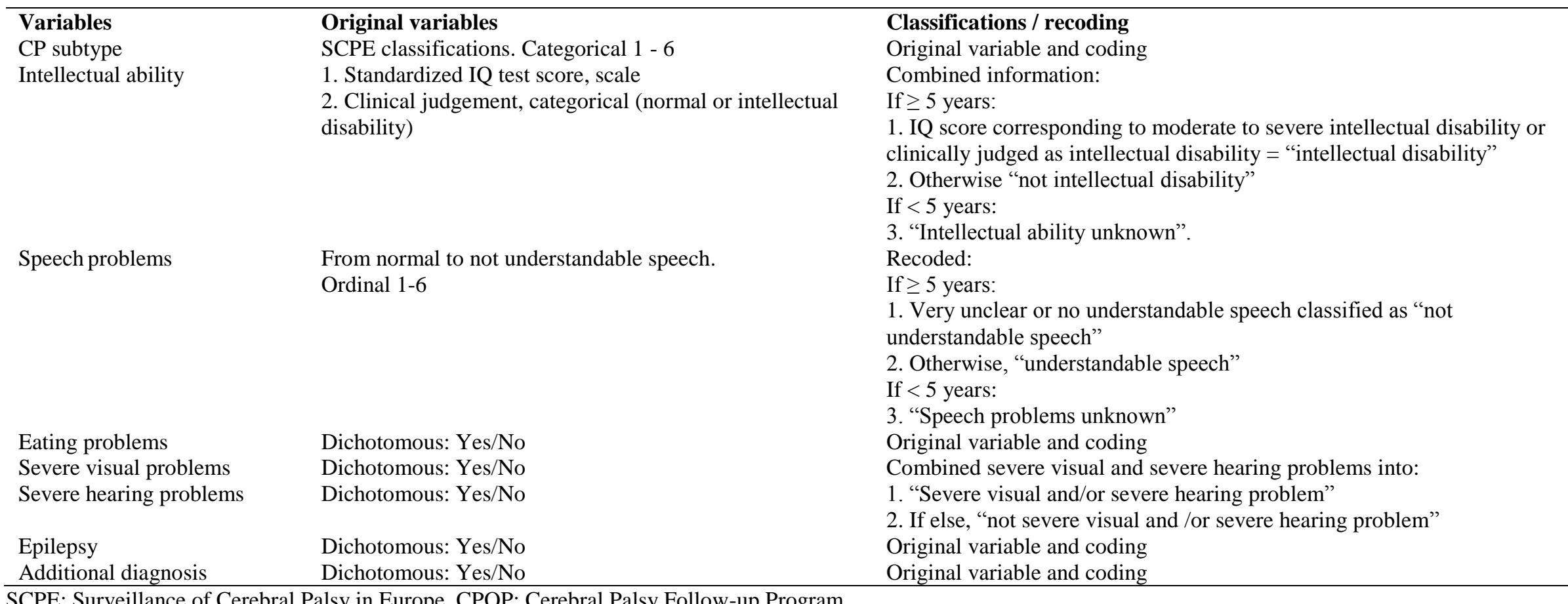


Table 3: Distribution of physical therapy frequency $(\mathrm{N}=987)$

\begin{tabular}{lc}
\hline & $\mathrm{n}(\%)$ \\
\hline$>5$ times per week & $10(1)$ \\
$3-5$ times per week & $100(10)$ \\
$1-2$ times per week & $601(61)$ \\
$1-3$ times per month & $188(19)$ \\
$<1$ time per month & $88(9)$ \\
\hline
\end{tabular}

Table 3: Distribution of physical therapy frequency; total and by GMFCS levels (N=987)

\begin{tabular}{|c|c|c|c|c|c|c|}
\hline \multirow{2}{*}{$\begin{array}{l}\text { Physical therapy } \\
\text { frequency }\end{array}$} & \multirow{2}{*}{$\begin{array}{l}\text { Total } \\
\mathrm{n}(\%) \\
\end{array}$} & \multicolumn{5}{|c|}{ GMFCS levels (\%) } \\
\hline & & $\mathrm{I}$ & II & III & IV & $\mathrm{V}$ \\
\hline$>5$ times per week & $10(1.0)$ & 0.7 & 1.1 & 3.3 & 0.9 & 0.0 \\
\hline 3-5 times per week & $100(10.1)$ & 5.2 & 6.4 & 19.0 & 11.9 & 22.1 \\
\hline 1-2 times per week & $601(60.9)$ & 50.8 & 64.2 & 74.4 & 70.6 & 69.5 \\
\hline 1-3 times per month & $188(19.0)$ & 27.8 & 20.9 & 3.3 & 11.0 & 8.4 \\
\hline$<1$ time per month & $88(8.9)$ & 15.5 & 7.5 & 0.0 & 5.5 & 0.0 \\
\hline
\end{tabular}


Table 4. Mean change (95\% CIs) in GMFM-66 percentiles by physical therapy frequency based on complete cases (left columns) and multivariable adjusted based on imputed data (right column).

\begin{tabular}{|c|c|c|c|c|c|c|c|c|c|c|c|c|}
\hline \multirow[b]{4}{*}{ Intercept } & \multicolumn{4}{|c|}{$\begin{array}{c}\text { Unadjusted model, complete } \\
\text { cases }(n=814)\end{array}$} & \multicolumn{4}{|c|}{$\begin{array}{l}\text { Adjusted model, }{ }^{*} \text { complete cases } \\
(n=814)\end{array}$} & \multicolumn{4}{|c|}{$\begin{array}{l}\text { Multivariable adjusted model, } * * * \\
\text { imputed data }(\mathbf{n}=814)\end{array}$} \\
\hline & \multirow{2}{*}{$\begin{array}{c}\Delta \\
\text { percentiles }\end{array}$} & \multicolumn{2}{|c|}{$95 \% \mathrm{CI}$} & \multirow[t]{2}{*}{$p$} & \multirow{2}{*}{$\begin{array}{c}\Delta \\
\text { percentiles }\end{array}$} & \multicolumn{2}{|c|}{$95 \% \mathrm{CI}$} & \multirow[t]{2}{*}{$p$} & \multirow{2}{*}{$\begin{array}{c}\Delta \\
\text { percentiles }\end{array}$} & \multicolumn{2}{|c|}{$95 \% \mathrm{CI}$} & \multirow[t]{2}{*}{$p$} \\
\hline & & Lower & Upper & & & Lower & Upper & & & Lower & Upper & \\
\hline & -0.2 & -2.4 & 1.9 & 0.835 & 0.9 & -1.4 & 3.3 & 0.450 & 2.0 & -1.4 & 5.5 & 0.242 \\
\hline \multicolumn{13}{|l|}{$\begin{array}{l}\text { Frequency of } \\
\text { physical therapy }\end{array}$} \\
\hline$>2$ times per week & 6.0 & 1.9 & 10.2 & 0.004 & 6.9 & 2.7 & 11.0 & 0.001 & 7.1 & 2.6 & 11.6 & 0.002 \\
\hline 1-2 times per week & 2.7 & 0.1 & 5.4 & 0.045 & 3.5 & 0.8 & 6.1 & 0.012 & 4.2 & 1.4 & 7.1 & 0.004 \\
\hline$<1$ time per week & Ref. & & & & Ref. & & & & Ref. & & & \\
\hline \multicolumn{13}{|l|}{ Number of } \\
\hline$>2$ & & & & & -6.1 & -10.4 & -1.7 & 0.006 & -5.6 & -10.3 & -0.8 & 0.021 \\
\hline $1-2$ & & & & & -2.8 & -5.2 & -0.3 & 0.029 & -2.3 & -5.0 & 0.4 & 0.093 \\
\hline None & & & & & Ref. & & & & Ref. & & & \\
\hline \multicolumn{13}{|l|}{ Epilepsy } \\
\hline Yes & & & & & & & & & -3.2 & -6.5 & 0.0 & 0.052 \\
\hline No & & & & & & & & & Ref. & & & \\
\hline
\end{tabular}

$\triangle$ percentiles: change in GMFM-66 percentiles from one observation to the next. Ref.: reference category *Adjusted for number of contractures.

**Adjusted for number of contractures, epilepsy, intellectual disability, pain, eating problems, visual and/or hearing problems, type of CP, participating in an intensive program, BoNT-A, ITB, surgery, using orthoses and additional diagnoses (only significant and borderline significant associations shown). 
Level I

$\mathrm{N}=442$ children

$\mathrm{N}=1498$ assessments

(2-9 assessments per child)

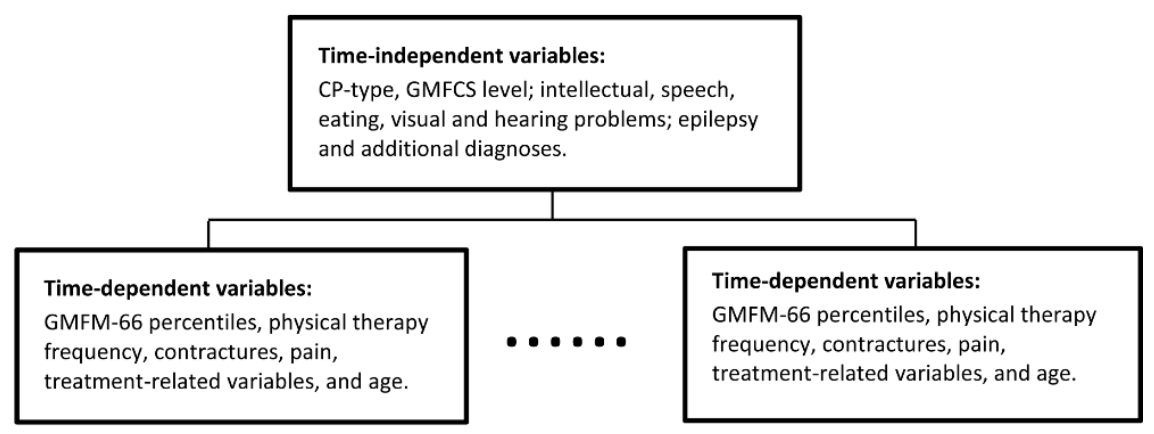

Figure 1

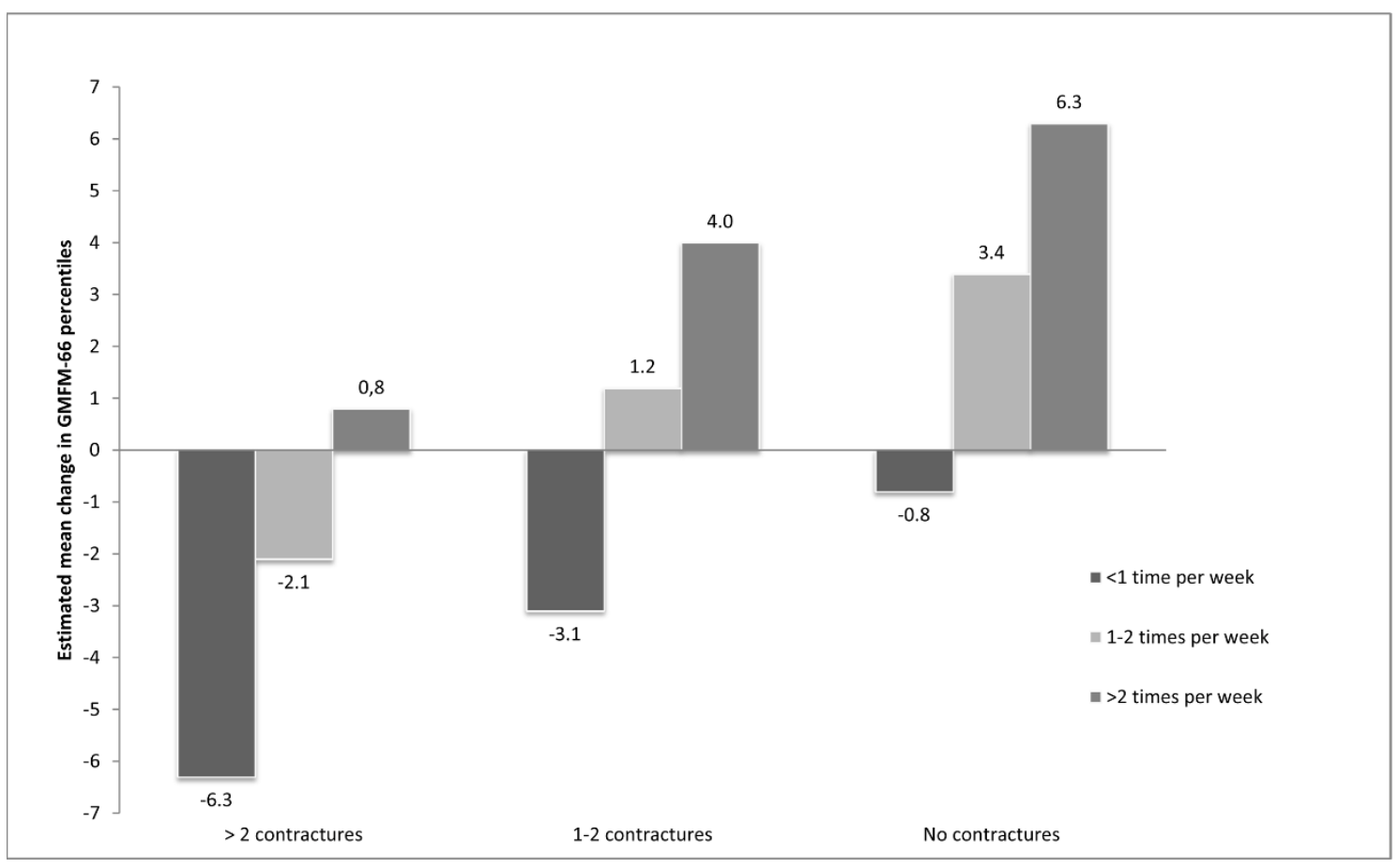

Figure 2 